\title{
A IMPRENSA PERIÓDICA NA PESQUISA EM HISTÓRIA DA EDUCAÇÃO: UM ESTADO DE CONHECIMENTO
}

\author{
Claudia Maria Petchak Zanlorenzi ${ }^{1}$
}

\section{Resumo}

O trabalho que aqui se apresenta buscou averiguar as teses e dissertações, entre 1970 e 2011 , que utilizam a imprensa, especificamente os periódicos educacionais, no período de consolidação dos ideais republicanos na sociedade brasileira. Primeiramente, realizou-se um levantamento preliminar de todas as pesquisas que têm a imprensa como fonte primária, seja jornal ou revista, para em seguida investigar quais utilizam revistas educacionais no recorte teórico proposto, início do século XX. Constatou-se pontos lacunares que possibilitaram o conhecimento sobre o posicionamento teórico nas teses e dissertações que se utilizam da imprensa como objeto de pesquisa para análise da educação, dando indícios da necessidade de trabalhos que utilizem os periódicos educacionais.

Palavras-chave: Estado de conhecimento. História da educação. Imprensa. Revista Pedagógica.

\section{THE PERIODIC PRESS IN THE HISTORY OF EDUCATION: A KNOWLEDGE STATUS}

\begin{abstract}
The research that is presented here, sought to investigate which theses and dissertations use the press, from 1970 to 2011, specifically educational journals, in a period of consolidation of Republican ideals in Brazilian society. First, there was a preliminary survey of all the research that has the press as a primary source, either newspaper or magazine, then to investigate which ones use the theoretical framework proposed, educational magazines, in the early twentieth century. Contacted points to lacunae, allowed the knowledge about theses and dissertations that use the press as a research subject for analysis of education and to give indications of the need for studies that utilize educational journals.
\end{abstract}

Keywords: Knowledge status. History of education. Press. Pedagogical Magazine.

\section{LA PRENSA PERIODICA EN LA INVESTIGACIÓN EN HISTORIA DE LA EDUCACIÓN: UM ESTADO DE CONOCIMIENTO}

\section{Resumen}


El trabajo que aquí se presenta buscó averiguar las tesis y disertaciones, entre 1970 y 2011 , que utilizan la prensa, específicamente los periódicos educativos, en el período de consolidación de los ideales republicanos en la sociedad brasileña. En primer lugar, se realizó un levantamiento preliminar de todas las investigaciones que tienen la prensa como fuente primaria, sea periódico o revista, para luego investigar cuáles utilizan revistas educativas en el recorte teórico propuesto en inicio del siglo XX. Se constató puntos lacunares que posibilitaron el conocimiento sobre el posicionamiento teórico en las tesis y disertaciones que se utilizan de la prensa como objeto de investigación para análisis de la educación, dando indicios de la necesidad de trabajos que utilicen los periódicos educativos.

Palabras-clave: Estado de conocimiento. Historia de la educación. Prensa. Revista Pedagógica.

\section{INTRODUÇÃO}

Aa pesquisas que utilizam a imprensa como fonte primária, mais precisamente os periódicos educacionais, já se fazem presentes de forma crescente nos meios acadêmicos, o que lhes confere o caráter de importante fonte histórica, com status de fonte primária e não apenas como ilustração de fatos. Dado a sua imediaticidade, é um material que expressa, em virtude da forma como representa as discussões, a manutenção de ideologias e as suas ressonâncias.

A imprensa periódica de cunho educacional, união entre dois aparatos ideológicos, a saber educação e imprensa, não apenas expressa em suas folhas questões pontuais de temáticas de ensino, mas também representa o movimento que se instaura na sociedade e que é fruto das relações de produção. Então, desvendar o que se veicula nos discursos desses periódicos é desvendar a forma como o trabalho educacional se concretiza, reflexo das vinculações ideológicas.

É sob essa perspectiva que o presente artigo tem por finalidade apresentar o Estado de conhecimento sobre a temática "A Imprensa periódica na pesquisa em História da Educação", realizado com o intuito de verificar as teses e dissertações, entre 1970 e $2011^{2}$, que utilizam os periódicos educacionais nos primeiros anos da República no Brasil como fonte primária de pesquisa, momento de consolidação dos ideais republicanos na sociedade brasileira, quando o país iniciava um novo regime com os ideais liberais advindos do sec. XVIII e XIX e que são expressão do capitalismo.

\section{A IMPRENSA PERIÓDICA NA PESQUISA EM HISTÓRIA DA EDUCAÇÃ̃O}


É nos impressos um campo que se pode observar a ideologia que permeia os discursos na sociedade e a legitimação dessa, haja vista ser um material de rápido alcance e repercussão. É um campo dinâmico para registrar as ideias e para a efetivação do consenso, o que garante uma gama de questões a serem perseguidas e estudadas pelo pesquisador, fornecendo dados que o levem a contextualizar e fazer as devidas relações para o desmonte do objeto. Estudos que utilizam a imprensa como fonte primária, a qual deve ser "[...] o cão guarda público, o denunciador incansável dos dirigentes" (MARX, 2006, p. 68), permitem apontar a ideologia que integra os discursos da época de uma dada sociedade determinada historicamente.

Fruto das relações sociais concretas, a ideologia com o papel de estar a serviço de uma classe, não pode ser considerada como algo especulativo, uma abstração, de criação apenas intelectual, elucubrações, mas sim que a própria ideologia surge das questões materiais da existência. Pela forma como os homens trabalham é que se processa a sua vida, a sua humanização; e é pela sua vida material que os homens produzem para a sua subsistência física e intelectual. Sobretudo, a forma como produzem, determina os tipos diferentes de pensar e "Mesmo as fantasmagorias correspondem, no cérebro humano, as sublimações necessariamente resultantes do processo da sua vida material que pode ser observado empiricamente e que repousa em bases materiais." (MARX; ENGELS, 1979, p. 25). Daí a necessidade cada vez mais presente de estudos que se encarreguem de analisar a imprensa na sociedade capitalista, a fim de possibilitar a compreensão de como se manifestam as relações de produção e a ideologia que as sustenta.

O pressuposto aqui exposto é que a imprensa é uma forma de disseminação da ideologia de uma classe. Então, a partir desse, buscou-se por meio de um estudo bibliográfico, realizar a organização do Estado de conhecimento, investigando quais pesquisas, entre 1970 e 2011, estão sendo realizadas sobre a imprensa na história da educação nos programas de pós-graduação das universidades brasileiras, especificamente com periódicos educacionais. A escolha desse recorte temporal do estado do conhecimento deu-se em virtude do período do surgimento das primeiras iniciativas de cursos de pós graduação, nível mestrado e doutorado ${ }^{4}$

O Estado de conhecimento (ou estado da arte) é uma pesquisa que visa um aprofundamento da produção acadêmica de uma temática em especial ${ }^{5}$. Essa forma de investigação proporciona um parâmetro sobre a quantidade das pesquisas efetivadas, e a partir dessa análise a aceitação do objeto, as convergências e divergências, os pressupostos teóricos e as lacunas, bem como as inovações na área e as permanências.

O trabalho que aqui se apresenta, buscou averiguar quais teses e dissertações utilizam a imprensa, especificamente os periódicos educacionais, para a disseminação da ideologia via formação de professores de caráter homogeneizador, entre 1889 a $1910^{6}$, momento de consolidação dos ideais republicanos na sociedade brasileira, quando o país iniciava um 
novo regime com os ideais liberais advindos do sec. XVIII e XIX e que são expressão do capitalismo. Para se chegar a esse objetivo, primeiramente foi feito um levantamento preliminar de todas as pesquisas que tem a imprensa como fonte primária, independente de qual modalidade, seja jornal ou revista.

Conforme dados da Coordenação de Aperfeiçoamento de Pessoal de Nível Superior $(\mathrm{CAPES})^{7}$, existem no Brasil, cento e treze (113) programas de pós graduação em Educação. No primeiro levantamento dos trabalhos, averiguou-se que vinte e três universidades, tanto pública como privada, em seus programas de pós-graduação têm em seus bancos de dados pesquisas que utilizam a imprensa. O objetivo dessa busca inicial foi apenas elencar as pesquisas em história da educação que têm como fonte primária os impressos, o que permitiu verificar a quantidade de estudos, bem como as universidades que têm se dedicado, em seus programas, às pesquisas desse porte.

Desse total, vinte e duas (22) universidades contém trabalhos que se dedicaram a investigar a imprensa e a educação, totalizando cento e trinta e sete (137) teses e dissertações. No período de 1970 a 2011, o número de pesquisas que foram feitas nos programas que priorizam a linha de história da educação são insipientes, em comparação com outras temáticas ${ }^{8}$. Vale destacar as seguintes universidades que contém o maior número de pesquisas em história da educação utilizando a imprensa: Universidade de São Paulo (USP), Universidade Federal de Minas Gerais (UFMG) e Pontifícia Universidade Católica de São Paulo (PUC/SP). Seria válido averiguar os motivos para o interesse na imprensa como fonte primária e nesse sentido algumas conjecturas podem ser feitas: a disponibilidade da fonte em arquivos ao alcance do pesquisador e a sua valorização como objeto de pesquisa no programa e entre os pesquisadores.

A situação da pouca utilização da imprensa em pesquisas demonstra que a imprensa como fonte primária é um fato recente, comprovado também pelo período no qual houve um emprego maior dessa fonte, entre 2006 a 2010. As questões que suscitam desse primeiro apanhado relacionam-se ao número reduzido de pesquisas que utilizam a imprensa e dentro desse aspecto, ao mesmo tempo, o aumento nos anos apontados acima. A validação da imprensa como fonte está relacionada à importância conferida a certas fontes em detrimento de outras, como também na legitimação dos dados contidos nos impressos, em virtude que é expressão do posicionamento dos responsáveis pelo jornal e revista, o que lhe confere, em certa medida, o caráter de subjetividade.

Além da importância ou não lhe dada como fonte primária, outro ponto a ser analisado é a sua significação como documento de expressão ideológica o que está condicionado a que objetivo se propõe a pesquisa. Já muito se discute sobre as relações intrínsecas entre educação e imprensa ${ }^{9}$, todavia o número restringido de estudos demonstra que a mesma é insuficientemente considerada como lócus para uma investigação direcionada 
sobre a ideologia, ou melhor, como uma via para desmascarar as contradições que movimentam as relações sociais e que estão presentes no contexto educacional.

O que se deduz desse fato, é que se considera que para efetivar uma pesquisa em educação, essa deva direcionar seus objetivos para a educação formalizada, com fontes específicas desse universo. Diante do exposto, a imprensa por não fazer parte desse universo, não lhe é dado a credibilidade de fonte legítima, aparecendo muitas vezes como coadjuvante e apenas para ilustrar um fato, sem uma devida reflexão de que a educação é a expressão das questões concretas que convergem das relações sociais e a imprensa é um ótimo documento para verificar tais questões, dado ser expressão do cotidiano.

O esclarecimento dessa situação também pode ser examinado ao se observar que do total desses trabalhos sessenta (60) teses e dissertações têm como objeto de estudo, revistas periódicas que são direcionadas a um público alvo: os profissionais de educação. Os demais são para jornais populares de circulação diária, entidades religiosas ou direcionadas ao público infantil ou feminino.

O número de pesquisas com periódicos educacionais, que são impressos diretamente relacionados ao universo educacional e não se desvinculam desse, ao mesmo tempo em que apontam para a problemática acima citada - a imprensa como coadjuvante, haja vista que em seu conteúdo são abordados temas sobre a educação diferente da imprensa popular - também sugerem numa mudança nas investigações e no foco sobre a história da educação, ultrapassando o ambiente estritamente escolar.

Esse material, apesar de ser específico e direcionado ao público docente, circula na sociedade expressando uma ideologia a partir da veiculação de conceitos, teorias, metodologias, entre outros, submetendo a uma exposição, a uma avaliação e convencimento do repertório. Daí a importância do seu desmonte e do olhar do pesquisador, pois o fato de ser impresso implica na expressão prévia de um ponto de vista que foi aceito por um grupo, principalmente quando são expostas opiniões da própria categoria de trabalho. Essa validação vem acompanhada pela intenção do convencimento, que porventura leva a uma uniformização dando "[...] aos pensamentos a forma de universalidade, representando-os como únicos, razoáveis, os únicos verdadeiramente válidos.” (MARX; ENGELS, 1979, p. $57)$.

Desmembrar de forma consciente todas as questões que envolvem a organização de um periódico educacional e os temas nele veiculados, fornece elementos que ao expor o universo educacional, retratam os interesses que permeiam a sociedade da época pesquisada. Por outro lado, essa intencionalidade homogeneizadora também oportuniza ao público alvo o conhecimento de outras propostas, de crítica às exposições feitas e principalmente no entendimento das contradições que emergem na sociedade. Essa relação entre conformação e superação, faculta ao pesquisador observar nos periódicos educacionais as artimanhas e a 
Artigo

doi: $10.20396 /$ rho.v18i2.8652374

formas de sedução que a ideologia assume para a garantia da hegemonia, via materialidade de um modelo pedagógico que evidencia os projetos reservados à educação.

Os primeiros periódicos pedagógicos de caráter nacional tiveram sua consolidação a partir da década de 1880, e do final do século XIX para o início do século XX multiplicaramse essas edições pedagógicas (CATANI, 1996, p. 123), organizadas em um contexto liberal, no qual a instrução escolar era considerada o caminho para o progresso.

Questões outras podem suscitar uma reflexão sobre esse "moderno" mecanismo de propagação de ideias: se a educação era considerada a panaceia para sociedade recém saída do regime escravocrata, então se fazia necessário atingir um maior contingente de público, angariando mais adeptos da ideologia em vias de consolidação: o liberalismo. Os periódicos educacionais cumpriram esse papel, principalmente em virtude de que tinham por objetivo a formação docente em um período em que essa formação era escassa, portanto são frutos desse contexto e como tal foram bem utilizados como objeto de uniformização. Entretanto, o número de periódicos também permite refletir se essa atenção especial à instrução era verdadeira.

Com fins pedagógicos e uma clientela específica, os periódicos educacionais eram mantidos ou pelo Estado ou pela iniciativa privada - associação de professores e grêmios sendo esses dependentes de assinaturas e anúncios, fato o qual se pode atrelar às seguintes questões: a efemeridade da vida dessas revistas, a quem interessava, o espaço publicitário e ao próprio descaso com o ensino e a formação docente.

Das cinquenta e oito teses e dissertações que analisaram revistas educacionais, cinco (5) têm como recorte temporal os primeiros anos da república no Brasil, mais especificamente o início do século XX, época na qual as ideias liberais tomavam forma no país.

Palco de vários debates, o início da república é um período que possibilita compreender as várias formas utilizadas para a manutenção da ideologia e quais seriam os símbolos para a legitimação desse ideário, tanto os direcionados àqueles que não eram alfabetizados ${ }^{10}$, como por exemplo, os panteões em praças públicas, como àqueles que tinham acesso aos impressos. Desvendar esse ideário, via revistas educacionais, constitui-se uma pesquisa com vistas a refletir sobre o liberalismo como "[...] expressão historicamente necessária do modo de produção capitalista" (WARDE, 1984, p. 26) e as formas como foi se assumindo ao longo dos tempos, conforme a estruturação do capitalismo nas diferentes formações sociais.

As pesquisas feitas com o objetivo de utilizar o recorte teórico os anos iniciais da república (1889-1910), tendo como fonte primária as revistas educacionais são: a tese Educadores a meia-luz (um estudo sobre a revista de ensino da associação beneficente do professorado público de São Paulo: 1902-1918), de Denice Bárbara Catani, defendida pela Universidade de São Paulo, em 1989; pela Universidade Estadual Júlio de Mesquita 
Filho ( Marília), a dissertação A Eschola Publica: (1893-1897) um estudo da pedagogia paulista no século XIX, de Adriana Aparecida Pinto, em 2001; Pensar e escrever a leitura na escola: Revista de Ensino da associação beneficente do professorado público de SP (1902 - 1918), dissertação de mestrado, defendida na Universidade de São Paulo, por Maria Cristina Perez Vilas, em 2003; de Ana Lúcia Cunha Fernandes a tese de doutorado A santa causa da instrução e o progredimento da humanidade: Revistas Pedagógicas e construção do conhecimento pedagógico no Brasil e em Portugal no final do século XIX, defendida pela Pontifícia Universidade Católica do Rio de Janeiro, em 2004 e por fim Inquietações modernas: discurso educacional e civilizacional no periódico A Escola (1906-1910), de Caroline Baron Marach, dissertação de mestrado defendida em 2007, pela Universidade Federal do Paraná.

Das pesquisas supracitadas, teve-se acesso às seguintes: Inquietações modernas: discurso educacional e civilizacional no periódico a escola (1906-1910); A santa causa da instrução e o progredimento da humanidade: Revistas Pedagógicas e construção do conhecimento pedagógico no Brasil e em Portugal no final do século XIX, e livro Educadores a meia-luz (um estudo sobre a revista de ensino da associação beneficente do professorado público de São Paulo: 1902-1918) ${ }^{11}$, publicado em 2003.

Ao analisar essas pesquisas, não se tem como pretensão fazer uma historiografia ou uma descrição de dados, portanto não serão feitas exposições extensivas do conteúdo dos trabalhos e sim reflexões sobre quais delas analisam a imprensa vinculada à ideologia liberal, no início da república, conforme já foi exposto no início desse trabalho.

A dissertação de Caroline Baron Marach utiliza como fonte primária a revista "A Escola", feita por professores do Grêmio de Professores Públicos do Paraná, entre 1906 a 1910, em Curitiba. Fundamentando-se em autores como Benjamin ( 1994; 1989; 1986; 1975), Nóvoa (1997), Ricouer (1997) Moscateli (2003), buscou compreender “[...] as motivações desses colaboradores em escrever para o professorado paranaense e, principalmente, entender em que medida constituíram um grupo, reunido em torno de projetos e discursos que se tangenciavam" (MARACH, 2007, p. 12), e de um contexto linguístico específico, como por exemplo a ideia de modernidade.

A pesquisadora investiga por meio da linguagem dos escritores da revista, denominando-os de "educacionistas"12, e elite letrada da capital do Paraná, considerandoos intelectuais, o que permite inserir a pesquisa nessa categoria. Já na introdução comprova porque essa inclusão dos mesmos na categoria dos intelectuais, tendo como base três características:

[...] a assunção, por esses escritores, da missão de guiar a nação rumo ao progresso e ao desenvolvimento socioeconômico [...]; previam que, por meio da instância educacional, atingir-se-ia o progresso almejado para o país [...]; o estabelecimento de laços identitários evidenciados na criação de regras próprias de conduta, de 


\section{Revista HIIST'TEIDBR On-line}

ISSN: 1676-2584

Artigo

doi: $10.20396 /$ rho.v18i2.8652374

instituições culturais, de veículos de divulgação de idéias e de projetos compartilhados. (MARACH, 2007, p. 20-21).

Em sua dissertação, a autora em vários momentos aponta a relação entre os intelectuais e o contato com as ideias liberais fora da capital paranaense e a influência dessas em suas trajetórias como educadores e literatos. Seu estudo, rico em informações sobre o periódico, pode servir de base para pesquisas futuras sobre a revista analisada, a história da educação brasileira e a ressonância no estado do Paraná. O destaque do seu trabalho é a forma como investiga o "léxico político"13 comum desse grupo de intelectuais, aos quais indicam suas posições convergentes e os motivos para organizarem uma revista aos professores.

Como trata dos intelectuais que se destacavam nesse período na capital paranaense, apresenta dados biográficos preponderantes sobre os mesmos, suas obras além dos escritos da revista, a ousadia dos mesmos e as relações com o aparelho administrativo do Estado. Esse último item, em específico, fornece elementos para uma discussão sobre a ideologia liberal e a formação do estado republicano, o qual poderia ter um aprofundamento.

Seguindo o mesmo recorte temporal, final do século XIX e início do século XX, destacamos a tese de Ana Lúcia Cunha Fernandes sob o título "A santa causa da instrução" e o "progredimento da humanidade" Revistas Pedagógicas e construção do conhecimento pedagógico no Brasil e em Portugal no final do século XIX, defendida na Pontifícia Universidade Católica do Rio de Janeiro, em 2004.

Fundamentando-se na História Cultural, tendo como autores Antonio Nóvoa, Marta Chagas de Carvalho, Roger Chatier, a pesquisadora utiliza o recorte temporal no final do século XIX, justificando que "[...] situaria nesse período o início da construção de um discurso educacional especializado [...]" (FERNANDES, 2004, p. 13), argumentando esse ser fruto da "[...] consolidação das ciências sociais e humanas e da emergência do modelo da escola de massas." (FERNANDES, 2004, p. 13). Seu trabalho é “[...] uma investigação sobre a gênese e o desenvolvimento do conhecimento pedagógico no Brasil e em Portugal, em finais do século XIX, visto através de revistas pedagógicas dos dois países" (FERNANDES, 2004, p. 13) e de que forma o mesmo se legitimou.

As revistas analisadas de forma comparada foram a Revista Pedagógica do Brasil e a Revista de Educação e Ensino de Portugal, aquela entre 1890 e 1896, e essa publicada, entre 1886 e 1900. A revista brasileira fazia parte Pedagogium do Museu Escolar do Distrito Federal, um órgão do governo, um projeto de "[...] implantação e desenvolvimento da educação nacional posto em prática a partir da implantação da República, em 1889." (FERNANDES, 2004, p. 45). A finalidade de tal revista era formação docente tendo como parâmetro a modernidade e a importância dos procedimentos científicos inseridos nesse parâmetro. Já a revista da Educação e Ensino de Portugal era de iniciativa privada tendo por finalidade dedicar um espaço às "[...] questões sobre a análise da importância da educação e 
de sua respectiva influência na evolução social” (FERNANDES, 2004, p. 47), que abre um espaço bem interessante para um estudo comparado que como afirma a autora, "[...] procurase também superar as abordagens muito centradas no interior das histórias nacionais, buscando situá-las no contexto da ocorrência de fenômenos transnacionais." (FERNANDES, 2004, p. 133).

A pesquisadora ao fazer esse estudo comparado defende como tese que:

[...] as Revistas Pedagógicas desempenharam um papel fundamental tanto na circulação quanto na produção de saberes (teorias, mas também idéias, modelos, práticas, experiências, etc.) ligados à educação e, conseqüentemente, na progressiva constituição de um campo disciplinar, no caso, o pedagógico, por meio da veiculação de um discurso educacional cada vez mais especializado. (FERNANDES, 2004, p. 47).

A tese da autora vai se delineando durante o trabalho como, por exemplo, quando dá destaque ao editorial, ou "[...] elementos da propaganda científica" (FERNANDES, 2004, p. 50), que mesmo sendo irregulares, refletem um posicionamento, os objetivos e interesse vinculados a uma ideologia: um discurso em educação portador de uma ideia de progresso. (FERNANDES, 2004, p. 55). Na análise do editorial das duas revistas, a autora elenca pontos de convergência entre as mesmas: a divulgação científica, publicação estrangeiras como modelo, público alvo professores, pretensão de formação docente. (FERNANDES, 2004, p. $51)$.

Outro ponto que a autora apresenta, quando analisa a escrita dos autores veiculados na revista e sua periodicidade, é a máxima da base da pedagogia como "ciência e arte de educar" apresentado pelas revistas e as reformas, metodologias, instruções que se delineiam a partir dessa insígnia e a proximidade com a Escola Nova, destacando a ideia errônea de que "[...] as formulações inovadoras teriam aparecido somente com os autores da Educação Nova", o que na verdade já estavam em cerne no surgimento da pedagogia. (FERNANDES, 2004, p. 186).

Conclui o trabalho comentando a importância de duas situações de sua tese: a metodologia utilizada, ou seja, o estudo comparado entre duas revistas rompendo "[...] com a ênfase exclusiva na dimensão nacional” (FERNANDES, 2004, p. 206) e o conteúdo veiculado nas duas revistas (FERNANDES, 2004, p. 207), sendo uma revista de cunho oficial e outra privada.

Utilizando uma revista pedagógica, editada inicialmente pela Tipografia Hennies \& Winninger, em São Paulo, como objeto de pesquisa no período inicial da república, destacase a dissertação de Adriana Aparecida Pinto sob o título A Eschola Publica: (1893-1897) Um estudo da Pedagogia Paulista no século XIX, defendida em junho de 2001, pela Faculdade de Filosofia e Ciência da Universidade Estadual Paulista "Júlio de Mesquista Filho" - UNESP- Campus Marília. 
A autora assinala, após leituras, que essa revista “[...] pode ser considerada a primeira publicação periódica pedagógica do Estado de São Paulo no período republicano" (PINTO, 2001, p. 15) e modelo para outros periódicos, fato que já atesta a importância desse trabalho em questão, haja vista que o estado de São Paulo era considerado modelo aos demais estados da federação, principalmente no que se refere à educação.

O periódico era editado pela primeira geração de formados da Escola Normal da capital, a saber: Oscar Thompsom, Benedicto Tolosa e Antonio Rodrigues Alves Pereira, que também desempenhavam funções na instrução pública como diretores e inspetores, fato que demonstra a relação próxima com o Estado, bem como condiciona seus posicionamentos. A revista "A Eschola", como relata a autora, teve duas fases: a primeira entre os anos de 1893-1894 e a segunda fase deu-se entre os anos de 1896-1897, com outro estilo tipográfico e arrojado para época: formato de livro.

As convicções dos editores podem ser analisadas nos comentários dos editoriais, que ao darem voz a seus ideais " [...] reservavam-se o direito de tecer comentário sobre a estrutura político administrativa do Estado de São Paulo, enfocando questões referentes à instrução pública” (PINTO, 2001, p. 36), sobretudo o embasamento em Pestalozzi, a partir do convencimento na adoção do método intuitivo por parte dos professores, como forma de atender às necessidades de um sistema educacional em fase de implantação.

Tendo como referencial teórico Bastos (1997), Catani (1989), Caspard (1997), Gondra (1996) e Nóvoa ( 1997), a autora comenta que o seu trabalho tem a "[...] intenção de contribuir para o alargamento e compreensão de uma determinada fonte em história da educação" (2001, p. 19), trazendo essa publicação para o “[...] campo dos debates e questões atuais, mediante sobretudo estudo da visão político - ideológica de seu conselho editorial, colaboradores e das orientações de natureza didático-metodológica.” (PINTO, 2001, p. 21).

As questões que permeiam seu trabalho dizem respeito aos seguintes itens: a busca pelos educadores editores da revista na elaboração de uma pedagogia paulista; revisitando uma prática de sucesso (segunda fase da revista); a revista enquanto manual de ensino para a formação de professores e fonte de consolidação de um método de ensino e o projeto editorial de A Eschola: três momentos de um mesmo tempo. O estudo dessas temáticas, que aborda nos capítulos fazendo um estudo detalhado da revista e dos assuntos tratados, possibilita uma síntese apurada dos temas explorados e dos autores.

Conclui que o estudo desse periódico contribuiu com informações “[...] que integram o quadro de referências de produções acadêmicas e científicas da área de história da educação." (PINTO, 2001, p. 113). Aborda que a revista foi um instrumento de solidificação das ideias e práticas corroboradas pelos editores e aponta a ausência de uma seção de leitores, o que demonstra que a imprensa foi amplamente utilizada para a disseminação dos ideais do grupo e mais amplamente os ideais republicanos, permeados pela ideologia liberal. 
Artigo

doi: $10.20396 /$ rho.v18i2.8652374

Todavia, a autora não se reporta a esse objeto e a relação com a ideologia especificamente, porém a forma como trata o periódico confirma tal situação implícita.

Marco das pesquisas que utilizam a imprensa periódica como objeto de estudo, Denice Bárbara Catani, em 1989, defende a sua tese de doutorado sob o título Educadores à meia - luz: um estudo sobre a Revista Ensino da Associação Beneficente do professorado Público de São Paulo ( 1902-1918), na qual suas observações “[...] destinamse a situar o aparecimento e o ciclo de vida da Revista de Ensino (1902-1918) e da Associação Beneficente do Professorado Público de São Paulo [...]." (CATANI, 2003, p. $15)$.

Pautando-se nesses objetivos, faz a análise do periódico educacional paulista supracitado dividindo-o em três fases: À sombra do poder: a Revista de Ensino sem a subvenção oficial (1905-1910); Educadores à meia luz: a Revista de Ensino sem a subvenção oficial (1905-1910) e À luz do poder: a Revista de Ensino "sob a imediata orientação" da diretoria geral de instrução pública (1911-1918), além de inicialmente no primeiro capítulo abordar sobre a Associação Beneficente.

Denice Bárbara Catani pretende alertar para que se “[...] reavalie o lugar 'menor' que tem sido atribuído ao período [...]" (CATANI, 2003, p. 219), correspondente à primeira década do século XX e que "[...] os estudos têm relegado a um plano secundário." (CATANI, 2003, p. 219). Esse objetivo da autora chama atenção, pois diante da pesquisa que aqui se apresenta das produções que utilizam a imprensa de 1970 a 2011, apenas as descritas acima são desse período. A autora fundamenta-se em Jorge Nagle (2004) quando alerta que "[...] depois dos anos iniciais do regime republicano instala-se um clima de modo geral alheado de discussões vigorosas e de plano inovadores. Os quinze primeiros anos deste século são marcados por um comportamento desalentador [...]." (NAGLE, 2004, p. 262).

O estudo da pesquisadora então pretende indagar "[...] sobre o significado desse "alheamento" ou dessa preocupação "exclusivamente voltada para questões técnicas" (CATANI. 2003, p. 17), constatando um movimento pouco semelhante no exame de estudos de história da educação que "Embora sejam quase unânimes ao constatar a ocorrência do 'surto de entusiasmo', fala-se do momento imediatamente posterior como de um tempo de desânimo, desilusões e frustrações, ao qual apenas os anos vinte vieram colocar um termo." (CATANI, 2003, p. 16).

Tecendo comentário sobre o "ciclo de vida" da Revista Ensino, utilizando metáforas nos títulos dos seus capítulos, emprega como categoria de pesquisa o poder estadual e a partir desse as temáticas mais proeminentes em cada período, baseando para a análise do objeto os estudos de Pierre Bourdieu ${ }^{14}$.

$\mathrm{Na}$ primeira fase, entre 1902 e 1904, a revista teve duas funções: “[...] a de orientadora (veículo de sugestões pedagógicas e dos métodos de ensino adequados à realidade das escolas públicas) e a de defensora (porta-voz das necessidades e direitos 
Artigo

doi: $10.20396 /$ rho.v18i2.8652374

docentes" (CATANI, 2003, p. 93), a primeira baseada na recuperação dos tempos áureos dos anos iniciais da República e a segunda cumprindo a função da Associação que se propunha a defender o grupo profissional, nos seus direitos, financeiramente, na saúde e juridicamente. Nesse período, a revista era impressa na tipografia do Diário Oficial, mantida pelo Estado, todavia ressalva "[...] inteira independência de idéias, e cada qual poderá emitir com a máxima franqueza e liberdade as suas opiniões.” (REVISTA ENSINO apud CATANI, 2003, p. 72). A segunda fase de 1905 a 1910 é o período de mais radicalização das opiniões, na qual "Ao deixar de receber a subvenção oficial, a Revista de Ensino inicia um período em que as críticas à situação das escolas públicas são mais violentas.” (CATANI, 2003, p. 108). É período em que é comparada com a revista "Escola Pública", contemporânea, porém com um perfil mais pedagógico. E por fim, a terceira fase, de junho de 1911 a dezembro de 1918, quando é editado o último volume do periódico. Esse momento pode ser considerado como “[...] uma expressão da derrota do projeto da Associação do Professorado e da ascensão da Diretoria Geral de Ensino, no que tange às pretensões de orientação e representação dos interesses do pessoal do magistério." (CATANI, 2003, p. 179). A revista assume o tom mais pragmático, com artigos que tratam de orientações metodológicas com temas mais “[...] consagrados sobre ensino: higiene, moral e civismo, disciplina e métodos seriam os principais." (CATANI, 2003, p. 189).

Haja vista que a autora se propõe a abordar sobre o "ciclo da vida" do periódico, sua análise histórica constitui-se, sem sombra de dúvidas, parâmetro para as demais pesquisas que foram produzidas em diante.

Observa-se a similaridade entre esse trabalho e de Caroline Baron Marach no que concerne na análise dos periódicos. Teriam os educadores paranaenses se baseados no periódico paulista? Evidências históricas permitem afirmar que havia influência, dado que o Estado de São Paulo era um marco tanto no que diz respeito aos aspectos econômicos, haja vista a produção cafeeira, como consequentemente o modelo para a instrução pública e os ideais republicanos de educação sob a responsabilidade do Estado. Marach afirma em sua pesquisa que os editores da revista "A Escola" estudaram na capital paulista, fato que sustenta tal afirmação e explica os pontos convergentes entre as pesquisas.

Pode-se a partir da análise dessas pesquisas acima abordadas, pontuar aspectos convergentes e que poderão incitar futuras pesquisas, por exemplo, o trabalho de Caroline Marach e de Denice Catani, fazendo um comparativo, dado que as duas revistas analisadas passam por fases de subvenção e corte do poder do Estado, analisando o teor das matérias e o posicionamento dos educadores frente à revista que ambos os casos também eram funcionários do governo. Nessa mesma linha de comparação, o trabalho de Adriana Aparecida Pinto em comparação com de Denice Catani, em virtude de que em certo ponto do ciclo de vida da Revista de Ensino, foi proposta seguir a mesma linha da revista A Escola Pública. 
Após essa análise geral das pesquisas estudadas para que o estudo não se inscreva apenas na análise descritiva e a guisa de conclusão percebem-se os seguintes pontos que se podem considerar como lacunares:

- não houve nas mesmas expressamente o objetivo de se investigar a ideologia presente no contexto histórico e nesse caso um aprofundamento do liberalismo e os reflexos na educação, principalmente quando são disseminados métodos e orientações pedagógicas como forma de universalização e homogeneidade, via o preceito de igualdade;

- o método de análise, conforme os autores utilizados em sua maior parte e quando explicitados, se fundamenta na História Cultural, não havendo um estudo mais profundo das contradições existentes na época e que influenciavam sob medida a educação, o que pressupõe da necessidade de estudos que propõe a estudar esse período, início do século XX a fim de desmistificar a visão de alheamento do período expresso por Jorge Nagle ao se reportar aos anos inicias do século, todavia a iniciativa de impressão desses periódicos já se constitui ao contrário. Faz-se necessário que se utilize do materialismo histórico como mirante e as categorias como totalidade, contradição e ideologia, a fim de não se incorrer no erro de uma análise descritiva com observações e as conclusões apenas do aparente, sem as devidas reflexões mais complexas, como foi mencionado no início desse artigo.

\section{CONSIDERAÇÕES FINAIS}

$\mathrm{O}$ exame dessas pesquisas possibilitou um amplo conhecimento sobre o posicionamento das pesquisas que se utilizam da imprensa como fonte primária para análise da educação, bem como dar indícios da necessidade de pesquisas que tratam do objeto fundamentados no materialismo histórico o que incitou a realização de uma pesquisa de doutorado sob o título $A$ revista $A$ Escola" $e$ a educação: um projeto liberal para o magistério no Paraná que propõe estudar a relação entre educação, imprensa e ideologia na sociedade brasileira, no início da república no Brasil, entre 1899 e 1910, defendida em 2014.

A pesquisa teve como principal fonte histórica a revista "A Escola" publicada em Curitiba-PR, no período de 1906 a 1910, por um grupo de intelectuais e professores da escola pública e que também foi objeto de estudo da Caroline Baron Marach, o que comprova que a partir do aporte teórico, vários estudos podem ser realizados com um mesmo objeto, o que suscita que há espaço para vários debates e esses enriquecem o aporte da História da Educação Brasileira.

Como objetivo propôs-se analisar a difusão da ideologia liberal, que ocultando as diferenças sociais, proclama o discurso de igualdade e da homogeneidade, legitimando as desigualdades sociais por meio da ideologia da igualdade natural entre os homens e não 
como característica de classe. A imprensa e a educação foram importantes instrumentos de divulgação desses e garantia da dominação da burguesia.

\section{REFERÊNCIAS}

CATANI, D. B.; BASTOS, M. H. C. (Org.). Educação em revista: a imprensa pedagógica e a história da educação. São Paulo: Escrituras, 2002.

CATANI, D. B. Educadores à meia - luz: um estudo sobre a Revista Ensino da Associação Beneficente do professorado público de São Paulo (1902-1918). Bragança Paulista: Ed. da EDUSF, 2003.

CATANI, D. B. A imprensa periódica educacional: revistas de ensino e o estudo do campo educacional. Revista Educação e Filosofia, v. 10, n. 20, p. 115-130, jul./dez. 1996.

FERREIRA, N. S. A. As pesquisas denominadas “estado da arte”. Revista Educação \& Sociedade, ano XXIII, n. 79, ago. 2002.

FERNANDES, A. L. C. A santa causa da instrução e o progredimento da humanidade: Revistas Pedagógicas e construção do conhecimento pedagógico no Brasil e em Portugal no final do século XIX. 2004. Tese (Doutorado) - Pontifícia Universidade Católica do Rio de Janeiro, Rio de Janeiro, 2004.

MARACH, C. B. Inquietações modernas: discurso educacional e civilizacional no periódico A Escola (1906-1910). 2007. 115 f. Dissertação (Mestrado em Educação) Universidade Federal do Paraná, Curitiba, 2007.

MARTINS, A. L. Revistas em revista: imprensa e práticas culturais em tempos de república, São Paulo (1890-1922). São Paulo: Ed. da EDUSP; Ed. da FAPESP; Imprensa Oficial do Estado de São Paulo, 2001.

MARX, K.; ENGELS, F. A ideologia alemã I. Lisboa: Presença, 1979.

MARX, K. Liberdade de imprensa. Porto Alegre: L\&P, 2006.

NAGLE, J. Educação e sociedade na Primeira República. In: FAUSTO, B. (Org.).

História da civilização brasileira: o Brasil Republicano - Sociedade e Instituições (18891930). 8. ed. Rio de Janeiro: Bertrand Brasil, 2004. v. 2, p. 261-291. t III.

NASCIMENTO, M. I. M. Formação de professores: perspectiva para a pesquisa em educação. In: SCHELBAUER, A. R.; LOMBARDI, J. C.; GOMES, M. C.;

NASCIMENTO, M. I. M. (Org.). Educação em debate: perspectiva, abordagens e historiografia. Campinas, SP: Autores Associados, 2006. 
PINTO, A. A. A Eschola publica: (1893-1897) um estudo da pedagogia paulista no século XIX. 2001. Dissertação (Mestrado) - Universidade Estadual Júlio de Mesquita Filho, Marília, 2001.

POCOCK, J. G. A.; MICELI, S. (Org.). Linguagens do ideário político. São Paulo: Ed. da EDUSP, 2003.

RIBEIRO, M. L. S. História da educação brasileira: a organização escolar. 4. ed. São Paulo: Moraes, 1982.

SCHELBAUER, A. L.; ARAÚJO, J. C. História da educação pela imprensa. Campinas, SP: Alínea, 2007.

VILAS, M. C. P. Pensar e escrever a leitura na escola: Revista de Ensino da associação beneficente do professorado público de SP (1902-1918). Dissertação (Mestrado) Universidade de São Paulo, São Paulo, 2003.

WARDE, M. Liberalismo e educação. 1984. Tese (Doutorado) - Pontifícia Universidade Católica de São Paulo, São Paulo, 1984.

\section{Notas}

${ }^{1}$ Doutora em Educação - Linha História e Política Educacional pelo Programa de Pós-Graduação da Universidade Estadual de Ponta Grossa (UEPG), professora da Universidade Estadual do Paraná (UNESPAR), Campus União da Vitória- PR. Membro do grupo de pesquisa HISTEDBR - Campos Gerais (UEPG) e do Núcleo de Estudos de Fundamentos da Educação e Métodos (NEFEM) - UNESPAR- UV. E mail: aecmari@gmail.com

${ }^{2}$ A data utilizada é referente à época de um trabalho de doutoramento, que iniciou em 2011. Cabe salientar que se faz necessária uma pesquisa a partir deste período.

${ }^{3}$ Para que não haja uma quebra na linha de pensamento, o presente artigo não terá subdivisões e sim serão marcadas em negritos as temáticas a serem abordadas.

${ }^{4}$ Há o texto "A imprensa periódica educacional: revistas de ensino e o estudo do campo educacional", de Denice Bárbara Catani, publicado na Revista Educação e Filosofia, v. 10, n. 20, p. 115-130, jul./dez. 1996, onde autora expõe trabalhos que utilizam revistas periódicas como objetos de estudo.

${ }^{5}$ Para sabe mais: FERREIRA, N. S. A. As pesquisas denominadas "estado da arte". Revista Educação \& Sociedade, ano XXIII, n. 79, ago. 2002. 257.

${ }^{6}$ Está sendo utilizado esse recorte temporal, dado uma pesquisa de doutorado que foi realizada com um periódico educacional do Paraná, a Escola, revista que foi publicada entre 1906 a 1910.

${ }^{7}$ Dados retirados do site da CAPES, com data atualização em 29 set. 2011. Disponível em: <http://www.capes. gov.br>. Acesso em: 06 out. 2011.

${ }^{8}$ Como exemplo de temática explorada tem-se o texto de Maria Isabel Moura Nascimento (2006) em que faz uma análise de produções que tem por objeto a formação docente no período de 1969 a 2002, totalizando 569 pesquisas.

${ }^{9}$ Para saber mais Schelbauer; Araújo (2007), Catani: Bastos (2002).

${ }^{10}$ A Taxa de analfabetos em 1890 era de $85 \%$, para $75 \%$ em 1900 . RIBEIRO, M. L. S. História da educação brasileira: a organização escolar. 4. ed. São Paulo: Moraes, 1982.

${ }^{11}$ Agradece-se às autoras Adriana Aparecida Pinto e Ana Lúcia Cunha Fernandes que prontamente enviaram cópias de suas pesquisas. 
${ }^{12}$ A autora explica que o termo é utilizado para referir-se "[...] àquele que pensava sobre a educação brasileira como uma questão social." (MARACH, 2007, p. 13).

${ }^{13} \mathrm{O}$ termo léxico é utilizado pela autora com a finalidade de analisar os vocábulos empregados pelo grupo. Para tanto, se fundamenta na obra POCOCK, J. G. A; MICELI, S. (Org.). Linguagens do ideário político. São Paulo: Ed. da EDUSP, 2003.

${ }^{14}$ A autora só faz menção a esse autor em nota de rodapé (p. 25) e nas referências. Não há mencionado outro autor, além da vasta referência de autores tratam especificamente do período e da história da educação, que possa ter lhe auxiliado no método de pesquisa.

Submetido em: 30/04/2018

Aprovado em: 25/05/2018

Publicado em: 22/06/2018 